\title{
Image Perception according to Face Shapes and Makeup Color Variation
}

\author{
Min-Hee Cho ${ }^{1}$, Jin-Hee Yang ${ }^{2 *}$ \\ ${ }^{1}$ Department of Clothing and Textiles, Chungnam National University, Daejeon, Korea \\ ${ }^{2}$ Department of Beauty Business, Bucheon University, Bucheon-si, Gyeonggi-do, Korea
}

\author{
*Corresponding author: Jin-Hee Yang, \\ Department of Beauty Business, Bucheon \\ University, 25 Sinheung-ro, 56beon-gil, \\ Bucheon-si, Gyeonggi-do 14632, Korea \\ Tel.: +82326100763 \\ Fax: +82326630114 \\ Email: jinee30@hanmail.net
}

Received September 22, 2016

Revised March 13, 2017

Accepted March 26, 2017

Published June 30, 2017

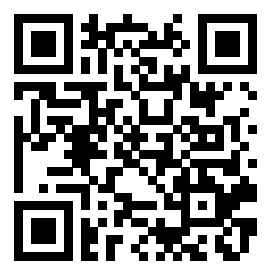

\begin{abstract}
Purpose: This study aimed to investigate the differences in image perception of adult females owing to variations in face shapes and makeup color. Methods: This experimental research study was conducted from August 1 to August 25, 2014 on 679 female participants. The participants were exposed to visual stimuli and asked to evaluate the images by responding to a questionnaire. Results: For the external factors that influence the image of women, 330 people of the respondents said it was makeup. It was the number one factor. And, 164 people thought it was the hairstyle, 115 people thought it was wardrobe, and 70 people thought it was skin. Regarding the differences in image perception according to face shapes, the participants perceived a long shape as gorgeous, a round shape as cute, a square shape as elegant, and an oval shape as natural. Regarding the differences in image perception owing to variations in makeup color, the orange tone was highly perceived to depict a gorgeous image while the pink tone was highly perceived to depict the elegant, natural, and cute images. Conclusion: The study proved that makeup is an external factor that significantly influences women's image perception; furthermore, it also revealed that face shapes and makeup colors create diverse perceptions, providing a clue regarding the factors that significantly affect women's image perception.
\end{abstract}

Keywords: Makeup, Color, Image, Face, Shape

\section{Introduction}

인간은 사회생활을 하면서 서로의 만남을 통해 관계를 맺으며 이 러한 관계 속에서 상대방을 관찰함으로써 상대방에 대한 인상을 형 성한다. Adams (1977)는 짧은 시간의 만남에서도 처음 본 사람의 나 이, 직업, 계층, 깔끔함, 성실성이 어느 정도 평가된다고 하였다. 이 와 같이 대인관계가 빈번한 현대사회에서 외모는 대인지각에 영향 을 주는 중요한 변인으로 인상을 형성하는데 매우 중요한 역할을 한다. 특히 여성의 경우 사회 참여와 전문화가 가속됨에 따라 자신 의 이미지를 표현할 기회가 많아지고 외모에 대한 관심도 더욱 높 아지게 되어 남성에 비해 외모에 더 집착하게 되고 다른 사람에게 어떻게 보이는가에 더 많은 관심을 갖는 경향이 있다(Gilmore et al, 1986; Graham \& Jouhar, 1981).

Song \& Park (2005)의 연구 결과에 의하면 외모는 모든 직업의
고용과 급료수준에 영향을 미치는데, 특히 직업 단계가 낮을수록 외 모가 많은 영향을 주는 것으로 나타났다. 즉 자신의 외적 이미지를 메이킹 함으로써 자신에 대한 자기 존중감을 높일 수 있으며 타인 에게 자신에 대한 긍정적 지각을 가져와 자신의 가치를 높여 사회 적 성공요인으로 작용하게 할 수 있다고 하였다. 이와 같이 외모는 현대 사회에서 중요한 위치를 차지하고 있으며, 매력적인 외모를 만들기 위해서는 먼저 자신의 외적 특성을 파악하는 것과 후천적인 노력이 필요하다. 후천적인 외모의 변화는 메이크업, 헤어, 의복 등 으로 변화 시킬 수 있으며 그 중에서도 메이크업은 여러 가지 화장 품과 도구를 이용하여 자기 얼굴의 장점을 한층 돋보이게 하고 자 신의 이미지를 전달하는 비언어적 수단이기도 하며, 전체적인 조화 를 고려한 토털 패션의 중요한 요소이다. 이러한 메이크업은 다양 한 얼굴 형태와 상호간의 색상에 의한 조화를 통해 메이크업의 이 미지가 창출되며 인상에도 큰 영향을 준다. 즉, 메이크업을 통해 어 
떤 이미지를 연출하고자 할 때 각 부분의 메이크업 형태와 색채를 조 화시켜 자유롭게 표현함으로써 외모를 변화시키는 것이라 할 수 있다.

Jang \& Shon (2006)에 의하면 여성의 아름다움은 얼굴의 형태 와 색채 그리고 재료의 미가 종합되어 나타나는데 그 중에서도 가 장 직접적으로 사람들의 눈에 호소하게 되는 것이 얼굴형과 색상 이라고 하였다. 얼굴형은 여성의 인상을 긍정적 또는 부정적으 로 지각시키기도 하며 미적인 측면에서 가장 중요한 신체의 부위 로 인식 되고 있다(Choi et al., 2010). 얼굴형을 분류하는 방법 은 주로 생체관찰방법(somatoscopy)과 계측방법(somatometry) 이 사용된다. 생체관찰방법은 전체적인 얼굴 윤곽을 시각적으로 판단하는 것이고, 계측방법은 얼굴을 측정하고 통계치를 이용하 여 얼굴형을 분류하는 것이다(Kim, 2007; Moon, 2000; Song \& Park, 2004). 계측방법에 의한 얼굴형의 명칭과 분류 기준을 보 면 크게는 각진형과 곡선형으로 나눌 수 있으며 얼굴의 중앙을 수 직으로 나누는 것이 그 기준이 되고 있다. 세부적으로 살펴보면 얼굴의 길이를 상안, 중안, 하안으로 나눈 비율에 따라 긴 얼굴과 짧은 얼굴로 나누고 얼굴 가로의 폭을 넓은 얼굴과 좁은 얼굴로 나누어 구분한다. 생체관찰방법은 타원형을 기준으로 하며, 이마 의 각과 아래턱 끝의 각이 높고 낮음에 따라 시각적으로 타원형, 둥근형, 사각형, 삼각형, 역삼각형, 마름모형, 긴형 등의 유형으
로 구분된다. 본 연구에서는 Eo et al. (2008)와 Kim (2007) 및 Kim \& Lee (2004)의 연구를 바탕으로 우리나라 성인 여성들에 게 가장 많이 볼 수 있는 타원형, 사각형, 둥근형, 긴형의 4 가지 얼굴형 유형을 선정하였으며 계측방법을 적용하여 컴퓨터 $3 \mathrm{D}$ 시뮬레이션을 통하여 측정 도구를 제작하였다.

메이크업의 색상 역시 이미지 지각에서 중요한 변인이다. Son $\& \operatorname{Kim}$ (2011)의 연구에 의하면 색조 메이크업을 한 얼굴에 대한 인상평가에서 근심없는, 사회적인, 재미있는, 노력하는, 안정적 인, 자신있는, 조직적인, 인기있는 등의 이미지로 지각되어 색조 메이크업이 이미지 지각에 영향을 주는 것으로 조사되었다. 자신 이 추구하고자 하는 이미지를 표현하기 위해서는 타고난 얼굴형 과 메이크업 색상변화에 따른 이미지 지각 요인을 살펴보는 것은 의미 있는 일이라고 생각된다. 따라서 본 연구에서는 성인 여성 을 대상으로 얼굴형과 메이크업 색상 변인에 대한 자극물을 통한 실험연구와 설문연구를 통해 여성의 이미지 지각에 미치는 요인 과 차이점을 규명하고자 한다.

Table 1. Photo of measurement tool on face shape

\begin{tabular}{|c|c|c|c|c|}
\hline \multirow{2}{*}{ Items } & \multicolumn{4}{|c|}{ Face shape types } \\
\hline & Oval shape & Square shape & Round shape & Long shape \\
\hline Photo images & $\infty$ & $\pi$ & 2 & 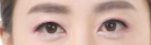 \\
\hline Head height (mm) & 250.0 & 231.3 & 230.6 & 271.9 \\
\hline Face length (mm) & 212.5 & 193.8 & 187.4 & 219.4 \\
\hline Head breadth (mm) & 170.8 & 160.8 & 163.9 & 188.5 \\
\hline Tragion breadth (mm) & 158.2 & 149.8 & 153.9 & 175.6 \\
\hline
\end{tabular}

Table 2. Photo of measurement tool on makeup color

\begin{tabular}{|c|c|c|c|}
\hline & & Makeup color tone type & \\
\hline & Pink tone makeup & Orange tone makeup & Red tone makeup \\
\hline Photo images & 2 & 2 & $\pi$ \\
\hline
\end{tabular}




\section{Methods}

\section{1. 조사 대상}

조사 대상은 대전 및 충청도 지역에 거주하고 있는 20-50대 성 인 여성 700 명을 대상으로 편의표본추출법으로 선정하였다. 자료 수집은 2014년 8월 1일부터 8월 25일까지 이루어졌으며, 자극물 을 조사대상자들에게 보여주고 설문지를 통해 이미지를 평가하는 방식으로 이루어졌다. 수집한 자료 중 무성의하고 불성실한 자료 21 부를 제외하고 통계분석에 사용된 설문지는 총 679 부이다.

\section{2. 측정 도구}

\section{1) 자극물 제작}

실험모델을 선정하기 위하여 20대에서 30대 초반 여성 20 명의 사진을 수집하여 10 인의 전문가 집단(미용학을 전공한 대학원생, 교수)에 의해 가장 자연스럽고 평범한 30대 여성을 실험모델로 선 정하였다. 선정된 모델의 메이크업은 가장 자연스러운 색상과 기 본형 형태로 표현하였으며 머리는 얼굴이 잘 드러나 보이도록 올백 으로 연출한 후 사진 촬영을 하였다. 촬영 시 얼굴 표정은 무표정하 게 조작하였으며, 사진의 배경색은 자극물의 이미지에 배경 효과 가 미치는 영향을 통제하기 위하여 흰색으로 제한하였다. 자극물 의 제작 방법은 실험모델의 사진을 FaceGen Modeller program

Table 3. External factors influencing image perception depend on the perceiver's characteristics

N (Column \%)

\begin{tabular}{|c|c|c|c|c|c|c|c|}
\hline \multirow{2}{*}{ Items } & & \multicolumn{4}{|c|}{ External factors } & \multirow{2}{*}{ Total } & \multirow{2}{*}{$X^{2}$} \\
\hline & & Hairstyle & Makeup & Wardrobe & Skin & & \\
\hline \multirow{4}{*}{ Age } & 20-29 years old & $38(23.2)$ & $74(22.4)$ & $40(34.8)$ & $11(15.7)$ & $163(24.0)$ & \multirow{4}{*}{$123.800^{* * *}$} \\
\hline & 30-39 years old & $57(34.8)$ & $71(21.5)$ & $36(31.3)$ & $15(21.4)$ & $179(26.4)$ & \\
\hline & $40-49$ years old & 32 (19.5) & $104(31.5)$ & $22(19.1)$ & $24(34.3)$ & $182(26.8)$ & \\
\hline & $50-59$ years old & $37(22.6)$ & $81(24.5)$ & $17(14.8)$ & $20(28.6)$ & $155(22.8)$ & \\
\hline \multirow{2}{*}{ Marital status } & Single & $59(36.0)$ & $93(28.2)$ & $46(40.0)$ & $17(24.3)$ & $215(31.7)$ & \multirow{2}{*}{$26.967^{* * *}$} \\
\hline & Married & 105 (64.0) & $237(71.8)$ & $69(60.0)$ & $53(75.7)$ & $464(68.3)$ & \\
\hline \multirow{4}{*}{ Education } & $\leq$ Graduation from high school & $43(26.2)$ & $108(32.7)$ & $21(18.3)$ & $22(31.4)$ & $194(28.6)$ & \multirow{4}{*}{$42.917^{* * *}$} \\
\hline & University student & $35(21.3)$ & $48(14.5)$ & $23(20.0)$ & $11(15.7)$ & $117(17.2)$ & \\
\hline & Graduation from university & $74(45.1)$ & $148(44.8)$ & $60(52.2)$ & $32(45.7)$ & $314(46.2)$ & \\
\hline & $\geq$ Graduation from master's degree & $12(7.3)$ & $26(7.9)$ & $11(9.6)$ & $5(7.1)$ & $54(8.0)$ & \\
\hline \multirow{8}{*}{ Monthly income } & $\leq 2$ million won & $33(20.1)$ & $62(18.8)$ & $17(14.8)$ & $15(21.4)$ & $127(18.7)$ & \multirow{8}{*}{$83.932^{* * *}$} \\
\hline & 2-3 million won & $38(23.2)$ & $73(22.1)$ & $27(23.5)$ & $11(15.7)$ & $149(21.9)$ & \\
\hline & 3-4 million won & $27(16.5)$ & 59 (17.9) & 24 (20.9) & $19(27.1)$ & 129 (19.0) & \\
\hline & 4-5 million won & 35 (21.3) & $56(17.0)$ & $21(18.3)$ & $8(11.4)$ & $120(17.7)$ & \\
\hline & 5-6 million won & $13(7.9)$ & $26(7.9)$ & $12(10.4)$ & $3(4.3)$ & $54(8.0)$ & \\
\hline & 6-7 million won & $5(3.0)$ & $21(6.3)$ & $7(6.1)$ & $2(2.9)$ & $35(5.2)$ & \\
\hline & 7-8 million won & $5(3.0)$ & $14(4.2)$ & $2(1.7)$ & $7(10.0)$ & $28(4.1)$ & \\
\hline & >8 million won & $8(4.9)$ & $19(5.8)$ & $5(4.3)$ & $5(7.1)$ & $37(5.4)$ & \\
\hline \multirow{11}{*}{ Job } & Student & 30 (18.3) & $32(9.7)$ & $19(16.2)$ & $6(8.6)$ & $87(12.8)$ & \multirow{11}{*}{$263.950^{* * *}$} \\
\hline & Professional job & $4(2.4)$ & $13(3.9)$ & $1(1.2)$ & $0(0.0)$ & $18(2.7)$ & \\
\hline & Office job & $18(11.0)$ & $39(11.8)$ & $18(15.7)$ & $4(5.7)$ & 79 (11.6) & \\
\hline & General professional & $14(8.5)$ & $14(4.2)$ & $20(17.4)$ & $4(5.7)$ & $52(7.7)$ & \\
\hline & Sales service job & $34(20.7)$ & $71(21.5)$ & $18(15.7)$ & $18(25.7)$ & $141(20.8)$ & \\
\hline & Specialized technical job & $8(4.9)$ & $12(3.6)$ & $3(2.6)$ & $2(2.9)$ & $25(3.7)$ & \\
\hline & Simple labor & $0(0.0)$ & $5(1.5)$ & $2(1.7)$ & $2(2.9)$ & $9(1.3)$ & \\
\hline & Housewife & $36(22.0)$ & $83(25.2)$ & $17(14.8)$ & $19(27.1)$ & 155 (22.8) & \\
\hline & Jobless & $3(1.8)$ & $11(3.3)$ & $3(2.6)$ & $4(5.7)$ & $21(3.1)$ & \\
\hline & Self-employment & $7(4.3)$ & $23(7.0)$ & $9(7.8)$ & $8(11.4)$ & $47(6.9)$ & \\
\hline & Others & $10(6.1)$ & $27(8.2)$ & $5(4.3)$ & $3(4.2)$ & $45(6.6)$ & \\
\hline
\end{tabular}

\footnotetext{
${ }^{* * *} p<0.001$
} 
(Singular Inversions, Canada)을 사용하여 4가지 얼굴형의 자극 물을 제작하였다. FaceGen Modeller program은 컴퓨터 시뮬레 이션 프로그램으로 얼굴형에 대한 계측 데이터를 입력하여 $3 \mathrm{D}$ 이 미지로 제작할 수 있으며, 연령, 성별에 따른 피부 텍스처를 선택 할 수 있어 좀 더 사실감을 높일 수 있는 장점이 있다. 선행연구에 서 유형화한 4 가지 얼굴형을 연구자가 시각적으로 평가하여 4명 의 모델을 선정하여 자극물을 제작할 경우, 얼굴형에 대한 정확 한 데이터를 적용하기 어려우며 피부의 질감, 얼굴윤곽의 형태 등 의 요소들이 지각자에 미치는 변수를 차단할 수 없다. 따라서 본 연구에서는 인체 사이즈 코리아에서 제시된 한국인의 표준형 얼 굴형 사이즈를 참고로 하여 동일한 조건의 모델 얼굴을 이용하여 FaceGen Modeller program으로 얼굴형 변인을 조작하여 자극물 을 제작하였다.

메이크업 색상변화에 따른 이미지 자극물은 동일한 실험모델의 얼굴에 메이크업 색상 변인을 핑크 톤, 오렌지 톤, 레드 톤의 3 가 지 유형으로 조작하였으며, 색상변화에 미치는 영향을 제한하기 위 하여 얼굴형은 타원형으로 제한하였다. Hwang (2002)은 타원형이 가장 표준적인 얼굴형으로 메이크업의 기준이 되며 모든 분위기의 연출이 가능한 형이라고 하였다. 눈썹형, 입술형 등의 얼굴 윤곽형 태 역시 기본형으로 제한하였다. 본 연구에 사용된 자극물의 이미 지는 얼굴형 4가지 유형(Table 1), 메이크업 색상 3가지 유형(Table 2)으로 총 7 개이며 최종 자극물은 컬러 이미지로 $95 \times 127 \mathrm{~mm}$ 사 이즈로 인화하였다.

\section{2) 설문지의 구성}

본 연구의 설문지 구성은 조사 대상자의 일반적 특성에 관한 5 문 항, 여성의 이미지 지각에 영향을 미치는 외적인 요소와 이미지 선호 도에 관한 3 문항으로 구성되었으며 이미지 지각 측정을 위한 총 14

Table 4. Preference according to the image

\begin{tabular}{lrc}
\hline Items & $\mathrm{N}$ & $\%$ \\
Gorgeous image & 70 & 10.3 \\
Elegant image & 96 & 14.1 \\
Natural image & 432 & 63.6 \\
Cute image & 81 & 11.9 \\
Total & 679 & 100.0 \\
\hline
\end{tabular}

개의 형용사 쌍을 의미미분척도로 사용하였다. 의미미분척도의 구 성을 위하여 Park et al. (2014)과 Ryu (2014) 및 Song \& Park (2004) 의 선행연구를 참고로 하였으며, 미용을 전공한 전문가 집단 10 명에 게 자극물을 제시하여 자유 기술 식으로 서술하게 한 후 메이크업 이 미지에 적합한 형용사 쌍 총 63 개를 1 차 수집하였다. 수집된 형용사 쌍의 타당성을 검증하기 위해 전문가 집단에 의해 사용 빈도수가 적 고 내용이 부적절한 것을 제외한 14 개의 형용사 쌍을 선정하였으며 7점 리커트 척도(Likert scale)로 요인분석에 사용하였다.

\section{3) 자료 분석}

본 연구의 자료 분석은 Statistical Package for the Social Sciences (SPSS) ver. 12.0 (IBM, USA)을 이용하였다. 조사 대상 자들의 일반적 특성은 빈도분석을 실시하였으며, 지각자 특성에 따른 이미지 지각에 영향을 미치는 외적 요소는 교차분석을 실시 하였다. 또한 이미지 지각의 차원을 밝히기 위하여 요인분석을 하 였으며 신뢰도 검사를 위해 Cronbach's $\alpha$ 를 산출하였다. 얼굴형과 메이크업 색상변화에 따른 이미지 지각의 차이를 알아보기 위해 $\mathrm{X}^{2}$ 검증, $\mathrm{t}$-test 검증, 다변량 분산 분석(multivariate analysis of variance)을 실시하였다.

\section{Results and Discussion}

\section{1. 조사 대상자의 일반적 특성}

조사 대상자의 일반적 특성은 전체 응답자 679 명 중 40 대 (26.8\%), 30대(26.4\%), 20대(24.0\%), 50대(22.8\%) 순으로 나타났 으며, 결혼여부는 기혼자가 464명(68.3\%), 미혼이 215명(31.7\%) 으로 조사되었다(Table 3).

\section{2. 여성의 이미지 지각에 영향을 주는 외적 요소 및 이미지 선호도}

1) 여성의 이미지에 영향을 미치는 외적 요소

여성의 이미지에 영향을 주는 외적 요소를 살펴본 결과, 전체 응답자 679 명 중 메이크업이라고 응답한 사람은 330 명(48.6\%) 으로 가장 많았으며, 헤어스타일 164 명(24.2\%), 의상 115 명 (16.9\%) 피부 70명(10.3\%) 순으로 조사되었다(Table 3). 직업을 제외한 연령, 결혼여부, 학력, 소득에 따른 모든 집단에서 메이

Table 5. Difference in image perception depends on face shape

\begin{tabular}{|c|c|c|c|c|c|c|}
\hline Factors & Oval shape & Square shape & Round shape & Long shape & $F$ & $p$ \\
\hline Gorgeous image & $4.45(1.00)^{1) a b}$ & $4.27(1.07)^{a}$ & $4.82(1.21)^{b c}$ & $5.07(1.01)^{c}$ & $5.230^{* *}$ & 0.002 \\
\hline Elegant image & $3.68(0.86)^{b}$ & $3.71(0.79)^{b}$ & $3.19(1.17)^{a}$ & $3.37(0.81)^{\mathrm{ab}}$ & $3.591^{*}$ & 0.015 \\
\hline Natural image & $4.64(0.83)$ & $4.50(0.74)$ & $4.53(0.87)$ & $4.41(0.90)$ & 0.574 & 0.633 \\
\hline Cute image & 3.95 (1.31) & 3.88 (1.09) & $3.98(1.03)$ & 3.52 (1.20) & 1.670 & 0.175 \\
\hline
\end{tabular}

${ }^{1)} \mathrm{M}$ (S.D.), mean (standard deviation); a, b, c, Duncan's multiple range test (a>b>c); ${ }^{*} p<0.05 ;{ }^{* *} p<0.01$. 
크업을 높게 평가하였다. 이는 메이크업의 경우 뷰티 솝을 방문 하지 않더라도 비교적 저렴한 비용으로 이미지를 연출할 수 있 는 장점으로 인해 가장 많은 집단이 선호하는 것으로 판단된 다. 직업의 경우, 일반전문직에서는 의상이라고 응답한 사람 이 가장 많았다. 단순노무직, 자영업자는 헤어스타일을 가장 낮 게 평가하였으며, 무직의 경우 헤어스타일과 의상을 가장 낮게 평가하였다. 판매서비스직에서는 의상과 피부를 가장 낮게 평 가하여 직업에 따라 유의미한 차이를 보여주고 있다 $(p<0.001)$.

\section{2) 여성의 이미지 선호도}

이미지 선호도에 대한 결과는 전체 응답자 679 명 중 자연스러 운 이미지 432명(63.6\%), 귀여운 이미지 81명(11.9\%), 화려한 이미 지 70명(10.3\%), 우아한 이미지 96명(14.1\%)인 것으로 조사되었다 (Table 4). 이와 같은 결과는 Barng \& Kim (2008)과 Song \& Park (2004)의 연구에서 한국인이 선호하는 이미지는 자연스럽고 편안 한 이미지로 나타난 연구결과와 일치한다. 자연스러운 이미지는 우 리나라를 비롯해서 중국, 태국, 일본 등에서도 선호하는 것으로 나 타났다(Kim \& Li, 2014).

\section{3. 얼굴형과 메이크업 색상변화에 따른 이미지 지각의 차이}

\section{1) 이미지 지각의 요인분석 및 신뢰도 측정}

얼굴형과 메이크업 색상변화에 따른 이미지 지각에 대한 차이 를 평가하기 위해 의미미분척도 형용사 문항에 대하여 주성분 분석 과 Varimax 회전방식법에 의한 요인분석을 시행한 결과 4 개의 요 인이 도출되었고 설명된 분산은 $60.102 \%$ 로 유의하다고 할 수 있 다. 첫 번째 요인은 "강렬한-부드러운", "화려한-수수한", "개성있 는-개성없는" 문항으로 구성되어 화려한 이미지라고 명명하였다. 두 번째 요인은 “고상한-천박한”, “우아한-우아하지 않은”, “세

Table 6. Preference according to the face shape

\begin{tabular}{lrr}
\hline Items & N & $\%$ \\
Oval shape & 196 & 28.9 \\
Square shape & 90 & 13.3 \\
Round shape & 283 & 41.7 \\
Long shape & 110 & 16.2 \\
Total & 679 & 100.0 \\
\hline
\end{tabular}

련된-촌스러운" 문항으로 구성되어 우아한 이미지라고 명명하였 으며, 세 번째 요인은 "자연스러운-인위적인", "현대적인-고전적 인", "청순한-요염한" 문항으로 구성되어 자연스러운 이미지라고 명명하였다. 네 번째 요인은 “귀여운-성숙해 보이는", "발랄한-점 잖은", "따뜻한-차가운" 문항으로 구성되어 귀여운 이미지라고 명 명하였다. 측정한 요인들의 신뢰성을 검증하기 위하여 내적 일관성 을 측정하는 방법인 Cronbach's $\alpha$ 를 산출하였다. 모든 요인이 0.6 이상의 신뢰도를 보여 본 연구에 사용된 측정도구의 신뢰도는 문제 가 없다고 판단된다.

\section{2) 얼굴형에 따른 이미지 지각 차이}

얼굴형에 따라 이미지 지각에 차이가 있는지를 알아보기 위해 다변량 분산 분석을 실시한 결과 요인1 (화려한 이미지)과 요인2 (우아한 이미지)에서 통계적으로 유의한 차이가 있는 것으로 나타 났다. 화려한 이미지에 대한 이미지 지각 정도가 가장 높은 얼굴형 은 긴형이며 가장 낮은 것은 사각형인 것으로 조사되었다 $(p<0.01)$. 우아한 이미지에 대한 지각 정도가 가장 높은 얼굴형은 사각형이 며, 가장 낮은 것은 둥근형인 것으로 조사되었다( $p\langle 0.05)$. 자연스 러운 이미지에 대한 지각 정도가 가장 높은 것은 타원형 얼굴형으 로 나타났으며 긴 얼굴형은 자연스러운 이미지의 지각이 가장 낮 게 나타났다. 귀여운 이미지에 대한 지각 정도가 가장 높게 나타난 것은 둥근형의 얼굴형으로 조사되었다(Table 5).

Kweon (1999)과 Son \& Kim (2011)의 연구에서 긴 얼굴형은 적 극적이고 화려한 이미지가 높게 나타났으며 타원형은 자연스러운 이미지가 높게 나타났다. Ha \& Han (2013)의 연구에서는 타원형 은 세련된 이미지로 나타났고 둥근형은 어려 보이는 이미지로, 긴 형은 성숙한 이미지, 사각형은 품위 있는 이미지로 나타나 본 연구 결과와 일치하고 있다. 이상의 선행연구와 본 연구 결과를 종합해 보면 긴 얼굴형은 전체적으로 귀여운 느낌보다는 여성스럽고 화려 한 이미지로 지각되고 있으며 자연스러운 이미지의 지각이 가장 낮 게 나타나는 것을 알 수 있다. 또한 둥근형은 대부분의 연구에서 어 려 보이고 귀여운 이미지로 지각되고 있으며 우아한 이미지의 지각 이 가장 낮게 지각되고 있다. 사각형은 우아하고 품위 있는 이미지, 타원형은 자연스러운 이미지로 지각됨을 알 수 있다.

Table 7. Difference in image perception depends on makeup colors

\begin{tabular}{lcccccc}
\hline Factors & Pink tone makeup & Orange tone makeup & Red tone makeup & $F$ & $p$ & Duncan \\
Gorgeous image & $3.18(1.19)^{1)}$ & $4.22(1.07)$ & $4.19(1.18)$ & $120.473^{* * *}$ & 0.000 & $B>A>C$ \\
Elegant image & $3.66(0.91)$ & $3.58(1.04)$ & $3.52(1.03)$ & $3.008^{*}$ & 0.05 & $C>B>A$ \\
Natural image & $5.09(0.81)$ & $4.65(0.85)$ & $4.75(0.92)$ & $27.050^{* * *}$ & 0.000 & $C>A>B$ \\
Cute image & $4.00(1.00)$ & $3.44(1.04)$ & $3.71(1.12)$ & $23.165^{* * *}$ & 0.000 & $C>A>B$ \\
\hline
\end{tabular}

${ }^{1)} \mathrm{M}$ (S.D.), mean (standard deviation); ${ }^{*} p<0.1 ;{ }^{* * *} p<0.001$. 


\section{3) 얼굴형의 선호도}

얼굴형의 선호도를 조사한 결과 전체 응답자 중 둥근형 283 명 (41.7\%), 타원형 196명(28.9\%), 긴형 110명(16.2\%), 사각형 90명 (13.3\%)으로 나타나 가장 선호하는 얼굴형은 둥근형으로 조사되었 다(Table 6). 이와 같은 결과는 Kim (2007)와 Song \& Park (2005) 의 연구결과와 일치하고 있다.

\section{4) 메이크업 색상변화에 따른 이미지 지각 차이}

메이크업 색상변화에 따른 이미지 지각의 차이는 모든 이미지, 즉 화려한 이미지 $(p<0.001)$, 우아한 이미지 $(p<0.05)$, 자연스러운 이미지 $(p<0.001)$, 귀여운 이미지 $(p<0.001)$ 에서 유의한 차이를 나타 내고 있다. 화려한 이미지는 오렌지 톤(4.22)이 가장 높게 지각되었 으며, 그 다음으로는 레드 톤(4.19), 핑크 톤(3.18)의 순으로 지각되 었다. 우아한 이미지는 핑크 톤(3.66)이 가장 높게 지각되었으며, 오렌지 톤(3.58), 레드 톤(3.52)의 순으로 조사되었다. 자연스러운 이미지는 핑크 톤(5.09), 레드 톤(4.75), 오렌지 톤(4.65)의 순으로 지각되었다. 귀여운 이미지는 핑크 톤(4.00)이 가장 높게 지각되었 고 레드 톤(3.71), 오렌지 톤(3.44) 순으로 나타났다(Table 7).

Cho \& Yang (2014)의 연구에서 핑크색은 가장 어려 보이는 이미 지의 색상으로 조사되었으며 많은 집단이 핑크를 가장 선호하는 것 으로 조사되었다. 본 연구에서도 핑크 톤이 화려한 이미지를 제외 한 모든 이미지 지각에서 높게 지각되는 것으로 조사되었으며 여성 들이 이미지 지각에서 가장 선호하는 색상임을 알 수 있다.

\section{Conclusion}

본 연구는 얼굴형과 메이크업 색상변화에 따라 이미지 지각의 차이를 일아 보기 위해 20-50대 여성을 대상으로 설문조사와 실험 연구를 병행하였다. 연구의 결과는 다음과 같다.

여성의 이미지 지각에 영향을 미치는 외적 요소는 전체적으로 메이크업이라고 응답한 사람들이 가장 많았으며 헤어, 의상, 피부 순으로 조사되었다. 연령, 결혼여부, 학력, 소득에 따른 모든 집단 에서 메이크업을 높게 평가하였으나 일반전문직은 의상을 가장 높 게 평가하였다. 헤어스타일은 단순노무직, 자영업자에서 가장 낮 게 평가되었으며, 의상은 40 대 연령, 50 대 연령, 고졸 이하, 전업주 부 집단에서 가장 낮게 평가되었다.

여성의 이미지 선호도에 대한 결과는 전체 응답자 679 명 중 자 연스러운 이미지가 432 명으로 가장 많았으며 우아한 이미지, 귀여 운 이미지, 화려한 이미지 순으로 조사되어 Kim (2007) 및 Song \& Park (2005)의 선행연구 결과와 일치하였다.

본 연구에서 여성의 이미지 지각에 영향을 미치는 요인은 화려 한 이미지, 우아한 이미지, 자연스러운 이미지, 귀여운 이미지의 4 가지 차원의 요인으로 도출되었다. 얼굴형에 따른 이미지 지각 차
이에서 긴 얼굴형은 화려한 이미지로 지각되었으며, 자연스러운 이 미지와 귀여운 이미지의 지각이 가장 낮게 나타났다. 또한 둥근형 은 귀여운 이미지로 지각되고 있으며 우아한 이미지의 지각이 가장 낮게 지각되었다. 사각형은 우아하고 품위 있는 이미지, 타원형은 자연스러운 이미지로 지각되는 것으로 나타났다. 또한 얼굴형은 둥 근형을 가장 선호하는 것으로 조사되었다.

메이크업 색상변화에 따른 이미지 지각의 차이에서 화려한 이미 지는 오렌지 톤이 높게 나타났으며 핑크 톤은 우아한 이미지, 자연 스러운 이미지, 귀여운 이미지 모두에서 높게 지각되었다. 이렇듯 얼굴형과 메이크업 색상은 여성의 이미지 지각 과정에서 그 유형에 따라 다양한 이미지를 형성하며 여성의 이미지 지각에 의미 있는 영향을 주는 단서로서 제공되고 있음을 확인할 수 있었다. 또한 본 인의 타고난 얼굴형에 대한 이미지 지각 요소를 파악하는 것은 여 성을 대상으로 하는 이미지 메이킹 연출에 도움이 될 수 있는 실질 적인 지침으로서의 역할과 함께 기초자료로서 활용될 수 있기를 기 대해본다. 본 연구는 여성의 이미지 지각의 변인을 얼굴형과 메이 크업의 색상에 국한하여 연구하였으며 좀 더 세분화된 변인에 대한 연구는 부족하였다. 후속연구에서는 여성뿐만 아니라 남성들까지 확대할 수 있는 좀 더 다양한 외적 요소와의 상관관계를 통해 이 미지 지각의 요인을 규명할 수 있는 심도 있는 연구가 이루어지길 바란다.

\section{References}

Adams GR. Physical attractiveness research: toward a developmental social psychology of beauty. Human Development, 20: 217-239, 1977.

Barng KJ, Kim JD. A study on various preferential make-up tendencies of cosmetic culture in the digital age: a focus on the convergence. Journal of the Korean Society of Cosmetology, 14: 284-301, 2008.

Cho MH, Yang JH. Study on women's preference on baby face with makeups. Asian Journal of Beauty and Cosmetology, 12: 875-883, 2014.

Choi EM, Yang JS, Kim YM, Lee YJ, Kim KY. A study on suitable makeup and hairstyle for round shape face woman. Journal of Investigative Cosmetology, 6: 15-24, 2010.

Eo SH, Son JY, Lee JS. Study on classification of faceline by hairline patterns. Journal of the Korean Society of Cosmetology, 14: 817-825, 2008.

Gilmore DC, Beehr TA, Love KG. Effects of applicant sex, applicant physical attractiveness, type of rater and type of job on interview decisions. Journal of Occupational and 
Organizational Psychology, 59: 103-109, 1986.

Graham JA, Jouhar AJ. The effects of cosmetics on person perception. International Journal of Cosmetic Science, 3: 199-210, 1981.

Ha K, Han B. Research on correlations between the appearance satisfaction level (face, skin and body), self-esteem and the feeling of happiness according to demographic characteristics: with high school students in Jinju region. Journal of Fashion Business, 17: 14-30, 2013.

Hwang YM. The make-up's influence on self-recognition \& satisfaction of beauty. Journal of the Korean Society of Beauty and Art, 3: 7-25, 2002.

Jang YJ, Shon YM. A study on image makeup for improving facial look. Journal of the Korean Society of Fashion Design, 6: 101-121, 2006.

$\mathrm{Kim} \mathrm{JH}$. The study of standard face shape analysis of adult women for make-up. Journal of the Korean Society of Costume, 57: 151-165, 2007.

Kim MJ, Lee SR. The study on the types of hair cut designs based on the face measurements of male college student. Fashion \& Textile Research Journal, 6: 740-748, 2004.

Kim SY, Li S. A study on point make up preference and image of Korean, greater Chinese, Japanese and Thai women. Asian Journal of Beauty and Cosmetology, 12: 709-717, 2014.

Kweon HS. Impression fromation based on facial shape 1.
The Journal of Design, 7: 0-9, 1999.

Moon NW. A study on women's face types classification by visual distinction and difference from the measurement. The Research Journal of the Costume Culture, 8: 133144, 2000.

Park YH, Kim BJ, Yang JH. A study on the evaluation of the impression formation of men and women applying for a personal hair color change. Asian Journal of Beauty and Cosmetology, 12: 693-700, 2014.

Ryu JW. The effect of female's make-up level and wear eyeglasses eyeglasses shape, perceiver's characteristics on the impression formation and attraction. Journal of the Korean Society of Cosmetology, 20: 155-166, 2014.

Son JY, Kim HS. Image perception on face shape and hair style depending on perceivers' characteristics. Journal of the Korean Society of Beauty and Art, 12: 107-124, 2011.

Song MY, Park OL. A study on recognition of face make-up and preference types in 20's female. Journal of the Korean Data Analysis Society, 7: 1337-1351, 2005.

Song MY, Park OL. A study on women's face types classification and shape differences. Journal of Fashion Business, 8: 76-90, 2004. 


\section{국문초록}

\section{얼굴형과 메이크업의 색상변화에 따른 이미지 지각에 관한 연구}

조민희 ${ }^{1}$, 양진희 ${ }^{2 *}$

1충남대학교 의류학과, 대전, 한국

${ }^{2}$ 부천대학교 뷰티융합비지니스과, 경기도 부천시, 한국

목적: 본 연구에서는 성인 여성을 대상으로 얼굴형과 메이크업 색상변화에 따른 이미지 지각의 차이점을 규명하고자 한다. 방법: 2014년 8월 1일부터 8월 25일까지 여성 679명을 대상으로 하였으며 자극물을 조사대상자들에게 보여주고 이미지를 설문지를 통해 평가하는 실험연구 방식으로 진행되었다. 결과: 여성의 이미지에 영향을 주는 외적 요소를 살펴본 결과 메이크업이라고 응답한 사 람은 330 명으로 가장 많았으며, 헤어스타일 164 명, 의상 115 명, 피부 70 명 순으로 조사되었다. 얼굴형에 따른 이미지 지각은 긴형 은 화려한 이미지, 둥근형은 귀여운 이미지, 사각형은 우아한 이미지, 타원형은 자연스러운 이미지로 지각되었다. 메이크업 색상변 화의 차이는 화려한 이미지는 오렌지 톤이 높게 지각되었고 핑크 톤은 우아한 이미지, 자연스러운 이미지, 귀여운 이미지 모두에서 높게 지각되었다. 결론: 메이크업은 여성의 이미지 지각에 가장 영향을 미치는 외적 요소이며 얼굴형과 메이크업 색상은 그 유형에 따라 다양한 이미지를 형성하며 여성의 이미지 지각에 의미 있는 영향을 주는 단서로서 제공되고 있음을 확인할 수 있었다.

핵심어: 메이크업, 색상, 이미지, 얼굴, 형태

\section{참고문헌}

권혜숙. 얼굴형과 여성의 인상 형성과의 관계에 대한 연구 1. 디자인연구, 7: 0-9, 1999. 김미정, 이상례. 남자대학생의 얼굴계측에 따른 유형별 헤어컷 디자인 연구. 한국의류산업학회지, 6: 740-748, 2004. 김수영, 리순화. 한국, 중화권, 일본, 태국 여성의 포인트 메이크업에 따른 선호 및 이미지 연구. 아시안뷰티화장품학술지, $12:$

709-717, 2014.

김정희. 메이크업을 위한 우리나라 성인 여성의 표준 얼굴 형태에 관한 연구. 복식, 57: 151-165, 2007.

류지원. 여성의 메이크업 수준과 안경착용 및 안경형태, 지각자 특성이 인상형성과 선호도에 미치는 영향. 한국미용학회지, 20: 155-166, 2014.

문남원. 시각적 판단에 의한 얼굴유형 분류와 계측 특성 연구. 복식문화연구, 8: 133-144, 2000.

박영해, 김범종, 양진희. 퍼스널 헤어컬러 변화를 적용한 남·녀의 인상형성 평가에 관한 연구. 아시안뷰티화장품학술지, 12 :

693-700, 2014.

방기정, 김주덕. 디지털시대의 향장미용 문화에 나타난 메이크업 선호도 경향과 특성: 융·복합화 현상 중심으로. 한국미용학 회지, 14: 284-301, 2008.

손지연, 김효숙. 얼굴형과 헤어스타일에 대한 지각자 특성에 따른 이미지 지각. 한국인체미용예술학회지, $12: 107-124$, 2011.

송미영, 박옥련. 20대 여성의 얼굴유형 분류 및 형태적 특성 연구. 패션 비즈니스, 8: 76-90, 2004. 어숙희, 손지연, 이재숙. 발제선 유형에 따른 얼굴형의 분류. 한국미용학회지, 14: 817-825, 2008. 장윤진, 손영미. 인상교정을 위한 이미지 메이크업 연구. 한국패션디자인학회지, 6: 101-121, 2006. 조민희, 양진희. 메이크업을 시술한 동안이미지에 대한 성인여성의 선호도에 관한 연구. 아시안뷰티화장품학술지, $12: 875-$ 883, 2014.

최은미, 양정순, 김유미, 이윤진, 김기영. 둥근형 얼굴에 어울리는 메이크업과 헤어스타일에 관한 연구. 대한미용학회지, 6 : $15-24,2010$. 
하경연, 한보현. 인구통계적 특성에 따른 외모만족도(얼굴, 피부, 몸매)와 자아존중감, 행복감과의 관계 연구: 진주지역 고등 학생을 중심으로. 패션 비즈니스, 17: 14-30, 2013.

황영미. 메이크업이 미에 대한 자기 인식 및 만족에 미치는 영향. 한국인체미용예술학회지, 3: 7-25, 2002. 


\section{中文摘要}

\section{脸型和化妆色彩变化的形象感知}

趙敏熙 ${ }^{1}$, 梁眞姬 ${ }^{2 *}$

${ }^{1}$ 忠南大学服装设计学科, 大田, 韩国

2富川大学美容融和商业学科, 京畿道富川市, 韩国

目的：根据脸型和化妆色彩的变化，探讨成年女性形象感知的差异。方法: 从2014年8月1日开始到8月25日，以679名女 性为研究对象, 受试者受到视觉刺激后, 实验研究通过问卷调查来评估图像的方式进行。结果: 女性形象的外因调查结 果显示，330名回答“化妆”，164名认为是发型，115名认为是衣服，而70名认为是皮肤。根据脸型，调查形象感知的差 异, 受试者认为长脸型为华丽型, 圆脸为可爱型, 方脸为优雅型, 椭圆脸形为自然型。根据化妆色彩变化的差异, 橙色 色调被认为是华丽型, 而粉红色的色调被高度认为描绘优雅, 自然, 可爱的形象。结论: 研究证明, 化妆是最影响女性 形象感知的外因, 脸型和化妆色彩按照类型形成多种形象, 此研究为影响女性形象感知提供重要线索。

关键词: 化妆, 色彩, 形象, 脸, 形态 